\title{
Mapeando a pesquisa em ensino de ciências: um olhar para as linhas de investigação no ENPEC na década de 2010
}

\section{Mapping research in science education: a look at the research lines at ENPEC in the decade of 2010}

\author{
Rosilene dos Santos Oliveira (rosiscientist@gmail.com) \\ Universidade Estadual de Maringá \\ Jaime da Costa Cedran (jccedran@uem.br) \\ Universidade Estadual de Maringá
}

Jheniffer Micheline Cortez (jheniffercortez@gmail.com)

Instituto Federal de Rondônia

Neide Maria Michellan Kiouranis (nmmkiouranis@gmail.com)

Universidade Estadual de Maringá

Resumo: A pesquisa que embasou o presente artigo, de natureza qualitativa, teve por objetivo analisar as linhas temáticas do Encontro Nacional de Pesquisa em Educação para a Ciência (ENPEC) na década de 2010. Para tanto, realizou-se o levantamento dos dados, referente ao quantitativo de trabalhos publicados em cada linha temática, nos anais do evento, nas edições de 2011 a 2019, de modo que estes dados foram tabulados e representados em um gráfico. Mediante a representação gráfica foi possível verificar o comportamento das linhas temáticas ao longo das últimas cinco edições do ENPEC. Desse modo, pode-se verificar que as publicações por linha temática, no período investigado, se comportaram de forma diversa, apontando para a consolidação e criação de algumas linhas, a supressão e a respectiva incorporação em outras, a estabilidade, bem como a diminuição ou aumento na produção de trabalhos. Os aspectos verificados neste estudo são oriundos dos diálogos entre diferentes pesquisadores, da ampliação de pesquisas e da consolidação da área e do evento.

Palavras-chave: educação científica; tendência de pesquisa; pesquisa educacional.

Abstract: This paper of qualitative nature aimed to analyze the thematic lines of the National Meeting on Research in Education for Science (ENPEC) in the decade 2010. For this purpose, a survey was made of the data, regarding the quantity of works published in each thematic line, in the annals of the event, in the 2011 to 2019 editions, so that these data were tabulated and represented in a chart. Through the graph representation it was possible to verify the behavior of the thematic lines over the last five editions of ENPEC. Thus, it can be verified that the publications by thematic line, in the period investigated, behaved in a different way, pointing to the consolidation and creation of some lines, the suppression and respective incorporation in others, the stability, as well as the decrease or increase in the production of papers. The aspects verified in this study come from the dialogues between different researchers, from the enlargement of research and the consolidation of the area and the event. 
Edição Especial: I SSAPEC - Simpósio Sul-Americano de Pesquisa em Ensino de Ciências

ISSN: 2595- $4520 \quad$ Vol. 4, n. 3. 2021

Keywords: science education; research tendency; educational research.

\section{REFLEXÕES INICIAIS}

A constituição da área de pesquisa em Ensino de Ciências, no Brasil, deu-se a partir da segunda metade do século XX, como consequência do contexto social, educacional, político e econômico do país (NARDI, 2014). O autor argumenta que a pesquisa em determinado campo investigativo vai se constituindo de forma dinâmica no decorrer do tempo e é influenciada por vários fatores, como a consolidação da área de Ensino de Ciências mediante a implementação dos projetos de ensino, a criação de políticas públicas voltadas à pós-graduação e das sociedades científicas, e os respectivos eventos científicos e periódicos na área, a partir da década de 1960.

Neste sentido, um dos marcos para a institucionalização desta área no Brasil foi a realização do I Encontro de Pesquisa em Educação para a Ciência (I ENPEC) em Águas de Lindóia (SP), em 1997, que reuniu aproximadamente 160 pesquisadores da área (NARDI, 2014). A partir das discussões iniciadas nesse evento, na segunda edição do ENPEC em Valinhos (SP), em 1999, criou-se a Associação Brasileira de Pesquisa em Educação em Ciências (ABRAPEC) com 106 pesquisadores. Desde então, a ABRAPEC é responsável pela realização do evento a cada dois anos e pela publicação, desde 2001, da Revista Brasileira de Pesquisa em Educação em Ciências (RBPEC), reunindo mais de mil associados atualmente (ABRAPEC, s.d.).

Realizaram-se doze edições do evento até o presente momento, em diferentes linhas de investigação e áreas de concentração. Iniciando com 70 trabalhos na primeira edição, na oitava edição em 2011, pela primeira vez, passou de mil publicações, reunindo 1152 trabalhos (LORENZETTI; SILVA; BUENO, 2015). Pela trajetória do evento, é perceptível sua consolidação em nível nacional, enquanto espaço de divulgação das pesquisas referentes ao Ensino de Ciências, da promoção do diálogo entre diferentes pesquisadores e estudantes da área (SLONGO; LORENZETTI; GARVÃO, 2015).

Diante disso, as pesquisas divulgadas nos ENPEC têm sido objeto de estudos de diferentes pesquisadores, dentre os quais destacam-se Delizoicov, Slongo e Lorenzetti (2007), que realizaram um estado da arte dos 10 anos de ENPEC (desde sua criação em 1997 até o ano de 2005). Os referidos autores verificaram por meio dos resultados obtidos a importância do evento para a consolidação do Ensino de Ciências enquanto 
Edição Especial: I SSAPEC - Simpósio Sul-Americano de Pesquisa em Ensino de Ciências

ISSN: 2595- $4520 \quad$ Vol. 4, n. 3. 2021

campo de pesquisa, bem como espaço privilegiado para a disseminação da produção científica da área no contexto brasileiro. Assim, a pesquisa permitiu a caracterização de aspectos referentes ao contexto, tendo em vista a procedência institucional destas pesquisas, as áreas de conhecimento, os níveis de ensino, o público-alvo, a diversidade de focos temáticos e problemas investigados, e também a evolução das edições do evento (DELIZOICOV; SLONGO; LORENZETTI, 2007, p. 1). Estes autores sinalizam ainda que, ao longo do referido período, o evento passou por modificações, de modo a oportunizar a publicização/divulgação de pesquisas da área, mas também apresentando propostas e implementação de iniciativas que contribuem para o direcionamento, a definição de "[...] caminhos da própria pesquisa e para a formação de pesquisadores" (DELIZOICOV; SLONGO; LORENZETTI, p. 4).

Nessa mesma perspectiva, outro trabalho neste viés é o de Slongo, Lorenzetti e Garvão (2015), que dando continuidade à pesquisa mencionada, analisaram os ENPEC desde 2007 até 2013, e verificaram resultados semelhantes aos obtidos no período anterior. No entanto, nesta pesquisa, especificamente, os referidos autores destacaram o caráter colaborativo das produções científicas, o aumento expressivo no quantitativo de trabalhos publicados, além da participação de instituições internacionais, aspectos que reforçam a expansão, representatividade e consolidação do próprio evento e da área de Ensino em Ciências.

Tendo isso em vista, os autores fundamentados em Silva e Gamboa (2011) nos trazem um alerta, qual seja o da necessidade de se realizarem balanços críticos a respeito dessa produção, notadamente, no âmbito dos programas de pós-graduação stricto sensu, considerando que nestes espaços a produção científica ocupa lugar privilegiado (SLONGO; LORENZETTI; GARVÃO, 2015, p. 7).

Além disso, mapeamentos por regiões brasileiras foram realizados, como por exemplo, as pesquisas envolvendo a análise das tendências teóricas e metodológicas de trabalhos publicados nos anais do XI ENPEC que analisam as produções oriundas de diferentes regiões brasileiras, quais sejam: nordeste (KRUPCZAK; SILVEIRA, 2019), norte (PEREIRA; SILVEIRA, 2019) e centro-oeste (SILVA; WERLANG; SILVEIRA, 2019). De modo geral, os resultados verificados nas referidas pesquisas revelam a fragilidade teórica e metodológica em boa parte dos trabalhos analisados de alguns 
Edição Especial: I SSAPEC - Simpósio Sul-Americano de Pesquisa em Ensino de Ciências ISSN: 2595- $4520 \quad$ Vol. 4, n. 3. 2021

eixos temáticos, o que foi evidenciado mediante a ausência da especificação, definição e fundamentação necessárias referentes a estes aspectos da pesquisa.

Ademais, no mapeamento realizado por Pereira e Silveira (2019) e Silva, Werlang e Silveira (2019), também verificam que, embora tenha ocorrido um aumento nas produções destas regiões investigadas, ainda há predominância das pesquisas desenvolvidas nas regiões sul e sudeste do país. Tal aspecto pode ser decorrente do fato de as edições do evento ocorrerem predominantemente nas regiões sul e sudeste do Brasil (com exceção da edição de 2019 que ocorreu na região Nordeste), podendo o deslocamento e a distância constituírem-se um dificultador para a participação de instituições e pesquisadores de outras regiões (SILVA; WERLANG; SILVEIRA, 2019).

Há também estudos que envolvem aspectos específicos em uma determinada área ou foco de interesse, dentre eles destacamos Lorenzetti, Silva e Bueno (2015) que mapearam as publicações em ensino de química e sua efetividade na prática docente, nos evidenciando a existência de um distanciamento entre aquilo que se tem pesquisado e o que de fato tem sido implementado na ação docente no contexto da sala de aula. E, Yamazaki e Delizoicov (2013) que analisaram a educação escolar indígena, constatando que esta temática ainda é pouco abordada nas pesquisas, ao que indica a necessidade de se desenvolverem estudos com esse foco articulado à formação de professores indígenas.

Ainda em relação a focos temáticos citamos a pesquisa de Silveira e Miranda (2019) em que investigaram as tendências dos trabalhos envolvendo a educação do campo. Por meio da pesquisa, os autores verificaram a predominância da Abordagem Temática Freireana como uma das principais abordagens no tocante ao processo de ensino e aprendizagem, ao passo que "[...] a formação inicial de professores para a Educação do campo e a Educação ambiental também obtiveram representatividade nos estudos analisados" (p. 94). E, Santos e Galieta (2019) pesquisaram a temática da Educação Inclusiva no Ensino de Ciências, revelando pouca incidência na publicação de pesquisas com esse foco no ENPEC, de modo que os trabalhos existentes se direcionam predominantemente à deficiência visual, com pouca atenção à deficiência intelectual, às altas habilidades e ao transtorno do déficit de atenção com hiperatividade (TDAH).

Como se pode verificar, o mapeamento dos diferentes aspectos da pesquisa em Ensino de Ciências é relevante em distintos contextos, em que se evidencia uma 
Edição Especial: I SSAPEC - Simpósio Sul-Americano de Pesquisa em Ensino de Ciências

ISSN: 2595- $4520 \quad$ Vol. 4, n. 3. 2021

tendência em estudos voltados a focos específicos de conhecimentos, apontando para a identificação de lacunas e contribuições para sua superação. Por outro lado, a perspectiva de trabalhos com foco mais abrangente também foi apresentada por alguns autores (DELIZOICOV; SLONGO; LORENZETTI, 2007; SLONGO; LORENZETTI; GARVÃO, 2015) nos quais são abordados um panorama dos trabalhos apresentados em algumas edições dos ENPEC.

Diante do exposto e considerando a relevância do evento para a comunidade de pesquisadores da área, o presente trabalho tem como objetivo analisar as linhas temáticas do ENPEC na década de 2010, a partir do número de trabalhos publicados em cada uma delas nas edições de 2011 a 2019 (VIII ENPEC a XII ENPEC, respectivamente).

\section{PERCURSO METODOLÓGICO: OS PASSOS CONSTITUTIVOS}

\section{DA PESQUISA}

Este estudo enquadra-se como uma pesquisa de natureza qualitativa, na medida em que busca compreender contextos e interpretar fenômenos voltados ao campo educacional (LÜDKE; ANDRÉ, 2013). Em específico, pode ser caracterizado como estudo de cunho documental, tendo os documentos como principal fonte de dados (FLICK, 2009; SÁ-SILVA; ALMEIDA; GUINDANI, 2009). Nesta pesquisa, os anais do ENPEC, disponíveis no site do evento, constituem nossos documentos de análise. Ademais, outro ponto que se adequa à caracterização de nosso estudo, é que a análise documental “[...] favorece a observação do processo de maturação ou de evolução de indivíduos, grupos, conceitos, conhecimentos, comportamentos, mentalidades, práticas, etc [...]" (TREMBLAY, 1968 apud CELLARD, 2012, p. 295).

Neste sentido, os contextos que buscamos compreender se referem às últimas cinco edições do Encontro Nacional de Pesquisa em Ensino de Ciências (VIII ENPEC Campinas/2011; IX ENPEC - Águas de Lindóia/2013; X ENPEC - Águas de Lindóia/2015; XI ENPEC - Florianópolis/2017 e XII ENPEC - Natal/2019), na tentativa de interpretar a variação na quantidade de trabalhos publicados nas diferentes linhas temáticas no decorrer do período estudado. Para essa interpretação, nos ancoramos em alguns autores, dentre os quais Slongo, Lorenzetti e Garvão (2015), Garcia et al. (2020), Gouvêa e Nascimento (2020), uma vez que suas pesquisas corroboram para a discussão de aspectos não realizados neste estudo, como por 
exemplo, a caracterização dos trabalhos publicados por meio de análise do conteúdo dos textos.

\subsection{Constituição e análise dos dados}

Os dados que constituem o corpus analítico da pesquisa foram obtidos por meio da busca pelos anais das edições do evento, disponibilizados na página eletrônica do ENPEC. Estes anais serão analisados individualmente, isto é, de acordo com cada edição do evento, no período de interesse considerando as linhas temáticas apresentadas, mediante a análise documental da relação linha de pesquisa e a quantidade de trabalhos apresentada em cada uma destas. De acordo com Sá-Silva, Almeida e Guindani (2009), esse momento da análise dos documentos “[...] propõe-se a produzir ou reelaborar conhecimentos e criar novas formas de compreender os fenômenos. [...]. O investigador deve interpretá-los, sintetizar as informações, determinar tendências e na medida do possível fazer a inferência" (p. 10).

Para que se possa visualizar as linhas temáticas constituintes do ENPEC e seus respectivos focos de abrangência apresentamos o Quadro 1.

Quadro 1 - Linhas temáticas constituintes do ENPEC e seus respectivos focos de abrangência

\begin{tabular}{|c|l|}
\hline $\begin{array}{c}\text { Linhas temáticas em } \\
\text { Educação em Ciências }\end{array}$ & \multicolumn{1}{|c|}{ Focos de abrangência de cada linha } \\
\hline $\begin{array}{c}\text { Ensino e Aprendizagem de } \\
\text { Conceitos (EA) }\end{array}$ & $\begin{array}{l}\text { Considerações epistemológicas sobre a natureza da } \\
\text { pesquisa; referenciais teóricos da pesquisa em } \\
\text { educação em ciências; educação em ciências como } \\
\text { campo científico; reflexões acerca de metodologias } \\
\text { e métodos de pesquisa. }\end{array}$ \\
\hline $\begin{array}{c}\text { Formação de Professores de } \\
\text { Ciências (FP) }\end{array}$ & $\begin{array}{l}\text { Análise de programas e políticas de formação } \\
\text { inicial e formação continuada; avaliações de } \\
\text { modelos e práticas de formação de professores de } \\
\text { Ciências para diferentes níveis e modalidades de } \\
\text { ensino (ex. séries iniciais, ensino superior, educação } \\
\text { de jovens e adultos); desenvolvimento profissional } \\
\text { de professores; pesquisa e formação de professores; } \\
\text { saberes docentes e práticas reflexivas. }\end{array}$ \\
\hline História, Filosofia e & \begin{tabular}{l} 
História e Filosofia da Ciência; Epistemologia e \\
\hline
\end{tabular}
\end{tabular}

Recebido em: 18/01/2021 


\begin{tabular}{|c|c|}
\hline $\begin{array}{l}\text { Sociologia da Ciência na } \\
\text { Ensino em Ciências (HFS) }\end{array}$ & $\begin{array}{l}\text { ensino de Ciências; natureza da Ciência; estudos } \\
\text { sociais da Ciência; sociologia do conhecimento } \\
\text { científico. }\end{array}$ \\
\hline $\begin{array}{l}\text { Educação em espaços não- } \\
\text { formais e divulgação } \\
\text { científica (ENF) }\end{array}$ & $\begin{array}{l}\text { História, políticas e práticas de divulgação científica } \\
\text { e sua relação com a Educação; relações entre } \\
\text { comunicação e educação; educação em museus e } \\
\text { centros de ciências; Divulgação científica e inclusão } \\
\text { social. }\end{array}$ \\
\hline $\begin{array}{c}\text { Tecnologias da informação e } \\
\text { comunicação no Ensino de } \\
\text { Ciências (TIC) }\end{array}$ & $\begin{array}{l}\text { Desenho e avaliação de recursos e ambientes } \\
\text { mediados por tecnologias para o ensino de Ciências; } \\
\text { metodologias de pesquisa baseada em design; } \\
\text { materiais multimídia e hipermídia; recursos áudios- } \\
\text { visuais; educação à distância. }\end{array}$ \\
\hline $\begin{array}{c}\text { Educação Ambiental e } \\
\text { Ensino de Ciências (EAM) }\end{array}$ & $\begin{array}{l}\text { Educação Ambiental; educação para o } \\
\text { desenvolvimento sustentável e ensino de Ciências. }\end{array}$ \\
\hline $\begin{array}{l}\text { Educação em Saúde e Ensino } \\
\text { de Ciências (ESD) }\end{array}$ & $\begin{array}{l}\text { Educação em Saúde; educação popular em saúde; } \\
\text { formação docente e profissional em saúde; } \\
\text { promoção da saúde. }\end{array}$ \\
\hline $\begin{array}{l}\text { Linguagens e Ensino de } \\
\text { Ciências (LIN) }\end{array}$ & $\begin{array}{l}\text { Abordagens discursivas; argumentação; interações } \\
\text { discursivas em salas de aula; leitura e escrita no } \\
\text { ensino de Ciências. }\end{array}$ \\
\hline $\begin{array}{l}\text { Alfabetização científica e } \\
\text { tecnológica, Abordagens CTS } \\
\text { e Ensino de Ciências (ACT) }\end{array}$ & $\begin{array}{l}\text { Relações entre Ciência, Tecnologia e Sociedade; } \\
\text { questões sociocientíficas; letramento científico. }\end{array}$ \\
\hline Curr & $\begin{array}{l}\text { Desenvolvimento de currículos; políticas de } \\
\text { currículo; seleção e organização do conhecimento } \\
\text { escolar; história das disciplinas científicas; reformas } \\
\text { curriculares, suas implementações e avaliações; } \\
\text { inovação educacional; currículos e culturas. }\end{array}$ \\
\hline $\begin{array}{l}\text { Avaliação e Educação em } \\
\text { Ciências (AVL) }\end{array}$ & $\begin{array}{l}\text { Aspectos metodológicos da avaliação em ensino de } \\
\text { Ciências; abordagens e práticas de avaliação; } \\
\text { avaliação institucional; avaliações de desempenho; } \\
\text { avaliação de programas; avaliação de sistema; } \\
\text { estudos comparativos internacionais (ex. PISA). }\end{array}$ \\
\hline $\begin{array}{l}\text { Diversidade, } \\
\text { Multiculturalismo e } \\
\text { Educação em Ciências } \\
\text { (DVM) }\end{array}$ & $\begin{array}{l}\text { Relações entre ensino de Ciências e temas tais como } \\
\text { inclusão, gênero, raça, etnia, classe, educação } \\
\text { indígena e de demais grupos sociais específicos, } \\
\text { políticas de ação afirmativa etc. }\end{array}$ \\
\hline $\begin{array}{l}\text { Processos e materiais } \\
\text { educativos em Ciências }\end{array}$ & $\begin{array}{l}\text { Análise de dinâmicas para trabalho em grupo (ex. } \\
\text { rodas de conversa; dramatização etc.); sequências }\end{array}$ \\
\hline
\end{tabular}




\begin{tabular}{|c|l|}
\hline (PMT) & $\begin{array}{l}\text { didáticas; livros didáticos; jogos educativos; } \\
\text { atividades práticas. }\end{array}$ \\
\hline $\begin{array}{c}\text { Histórico, análise e impactos de políticas públicas } \\
\text { para a Educação em Ciências em diferentes níveis e } \\
\text { modalidades de ensino (ex. séries iniciais, ensino } \\
\text { superior, educação de jovens e adultos); Legislação } \\
\text { Educacional e ensino de ciências; financiamento de } \\
\text { ações educacionais; fomento à pesquisa em } \\
\text { educação científica e tecnológica; políticas } \\
\text { educacionais e políticas de desenvolvimento e } \\
\text { inovação social, científica e tecnológica; programas } \\
\text { de vocação e iniciação científica; programas de } \\
\text { incentivo à docência; formação de professores de } \\
\text { ciências em nível de pós-graduação, lato e stricto } \\
\text { sensu; olimpíadas de ciências. }\end{array}$ \\
\hline $\begin{array}{c}\text { Questões teóricas e } \\
\text { metodolóncias (POL) } \\
\text { em Educação em Ciências } \\
\text { (QTM)* }\end{array}$ & $\begin{array}{l}\text { Consideraçães epistemológicas sobre a natureza da } \\
\text { pesquisa; referenciais teóricos da pesquisa em } \\
\text { educação em ciências; educação em ciências como } \\
\text { campo científico; reflexões acerca de metodologias } \\
\text { e métodos de pesquisa. }\end{array}$ \\
\hline
\end{tabular}

*Esta linha somente foi criada no IX ENPEC Fonte: ENPEC $(2011 ; 2013)$

Ressaltamos que nesta pesquisa, foram utilizados os nomes das linhas temáticas (Quadro 1), conforme consta na descrição do VIII ENPEC, de modo que na seção seguinte serão apontadas as mudanças que ocorreram a estas linhas considerando a trajetória do evento até o XII ENPEC.

Tendo em vista as linhas temáticas expressas no Quadro 1, apresentamos, na seção seguinte, os dados organizados e compilados com base nas referidas linhas e o quantitativo de trabalhos publicado em cada uma delas. Ademais, no decorrer dos anos as mesmas vêm sofrendo alterações, algumas delas foram suprimidas, outras fundidas, de acordo com as demandas trazidas nos trabalhos, o que se verifica por meio do quantitativo da produção. E outras ainda, considerando que a maior parte das linhas se mantiveram, passaram por pequenas alterações na nomenclatura. Dito isso, justificamos que neste trabalho, embora os nomes adotados refiram-se às linhas existentes na VIII edição do evento analisado (VIII ENPEC), preocupamo-nos em realizar ao longo da discussão as devidas correlações com as linhas de eventos anteriores e, deste modo, com as modificações em sua denominação. 
Edição Especial: I SSAPEC - Simpósio Sul-Americano de Pesquisa em Ensino de Ciências

ISSN: 2595- $4520 \quad$ Vol. 4, n. 3. 2021

Diante do exposto, na sequência apresentamos os resultados obtidos do processo de análise dos documentos (anais das cinco últimas edições do ENPEC) em relação às linhas temáticas e o quantitativo de trabalhos publicados, buscando traçar um movimento descritivo e interpretativo de o que se verificou e as nuances que podem ter contribuído para os aspectos que se mostram. Além disso, mencionamos algumas considerações quanto ao perfil dos participantes e a natureza das pesquisas (teórica e empírica) aceitas para submissão no evento.

\section{RESULTADOS E DISCUSSÕES}

Do processo analítico realizado na pesquisa, pode-se evidenciar que nas cinco edições do ENPEC investigadas houve oscilação no número total de trabalhos submetidos e apresentados, bem como no número de participantes no evento, conforme dados apresentados na Tabela 1.

Tabela 1 - Quantidade de trabalhos publicados em cada edição do ENPEC no período de 2011 a 2019

Edições do ENPEC VIII

IX $\mathbf{X}$ XI XII Total

Número de participantes 1920 1037 2553 1474 1208 8192

Número de trabalhos submetidos

1695

1526

1768

1840

1752

8581

\section{Número de trabalhos publicados}

1205

994

1282

1335

1246

6062

Fonte: Autoria própria.

O número de participantes e de trabalhos submetidos e publicados ao longo das edições do ENPEC demonstra a relevância desse evento para a comunidade da área, mantendo certa estabilidade independentemente do local de realização do mesmo. Isso, considerando-se que as edições em análise foram realizadas em diferentes regiões do país, sendo três no estado de São Paulo (VIII, IX e X ENPEC), uma em Santa Catarina (XI ENPEC) e uma no Rio Grande do Norte (XII ENPEC). 
Edição Especial: I SSAPEC - Simpósio Sul-Americano de Pesquisa em Ensino de Ciências ISSN: 2595- $4520 \quad$ Vol. 4, n. 3. 2021

A respeito dessa última edição, é importante sinalizar que sua realização na região nordeste, contando com o tema "Pesquisa em Educação em Ciências: Diferença, Justiça Social e Democracia", teve como intuito promover a ampliação e "[...] a oportunidade de fomentar novos diálogos, valorizando espaços acadêmicos públicos e culturais" (ENPEC, 2019, s. p.). Neste sentido, Nascimento e Gouvêa (2020) enfatizam que esse ENPEC de 2019 foi fortemente permeado por questões sociais e culturais entrelaçadas à Educação em Ciências, fato "[...] que pode ser interpretado à luz do cenário político brasileiro, marcado por uma série de medidas governamentais consideradas retrocessos no âmbito dos direitos sociais e humanos" (p. 473).

Em relação ao perfil dos participantes, com base no site da ABRAPEC (http://abrapecnet.org.br/wordpress/pt/enpecs-anteriores/), notamos que cerca de metade dos participantes do evento são acadêmicos de pós-graduação, com exceção da primeira edição analisada (ENPEC, 2011) a qual contou com a participação de um público composto em sua maioria por pesquisadores da área. Já na última edição avaliada, os alunos de graduação totalizam cerca de $13 \%$ dos participantes (ENPEC, 2019). Ainda sobre a edição mais recente, foi contabilizado também o número de professores da Educação Básica presentes no evento. Embora o número tangencie $10 \%$ do total de participantes, a presença destes professores é fundamental para que se vislumbre maior integração entre as pesquisas em Ensino de Ciências e a possibilidade de extrapolar de fato os resultados da pesquisa para e Educação Básica.

Em relação à natureza das pesquisas do ENPEC, são aceitos trabalhos inéditos e de pesquisa em Educação em Ciências dos tipos empírico e teórico, não sendo aceita a submissão de relatos de experiência ou projetos de pesquisa (ENPEC, 2019). Após a submissão, os trabalhos são encaminhados à avaliação às cegas a ser realizada por no mínimo dois árbitros (mestres e doutores) e, caso haja discordância entre os pareceres, há a avaliação por um terceiro parecerista (ENPEC, 2019). É importante mencionar que os trabalhos aprovados somente têm efetivada sua publicação nos anais do evento, após apresentação oral.

Desse modo, os trabalhos apresentados no evento foram separados por linhas temáticas, e posteriormente determinados os percentuais relativos a cada linha referente à respectiva edição do evento em análise. Os resultados estão expressos na Figura 1, por meio da qual é possível observar as temáticas mais recorrentes nos trabalhos 
Edição Especial: I SSAPEC - Simpósio Sul-Americano de Pesquisa em Ensino de Ciências

ISSN: 2595- $4520 \quad$ Vol. 4, n. 3. 2021

apresentados nas edições do ENPEC da última década, bem como verificar a tendência do percentual de trabalhos apresentados em cada uma dessas linhas no período analisado.

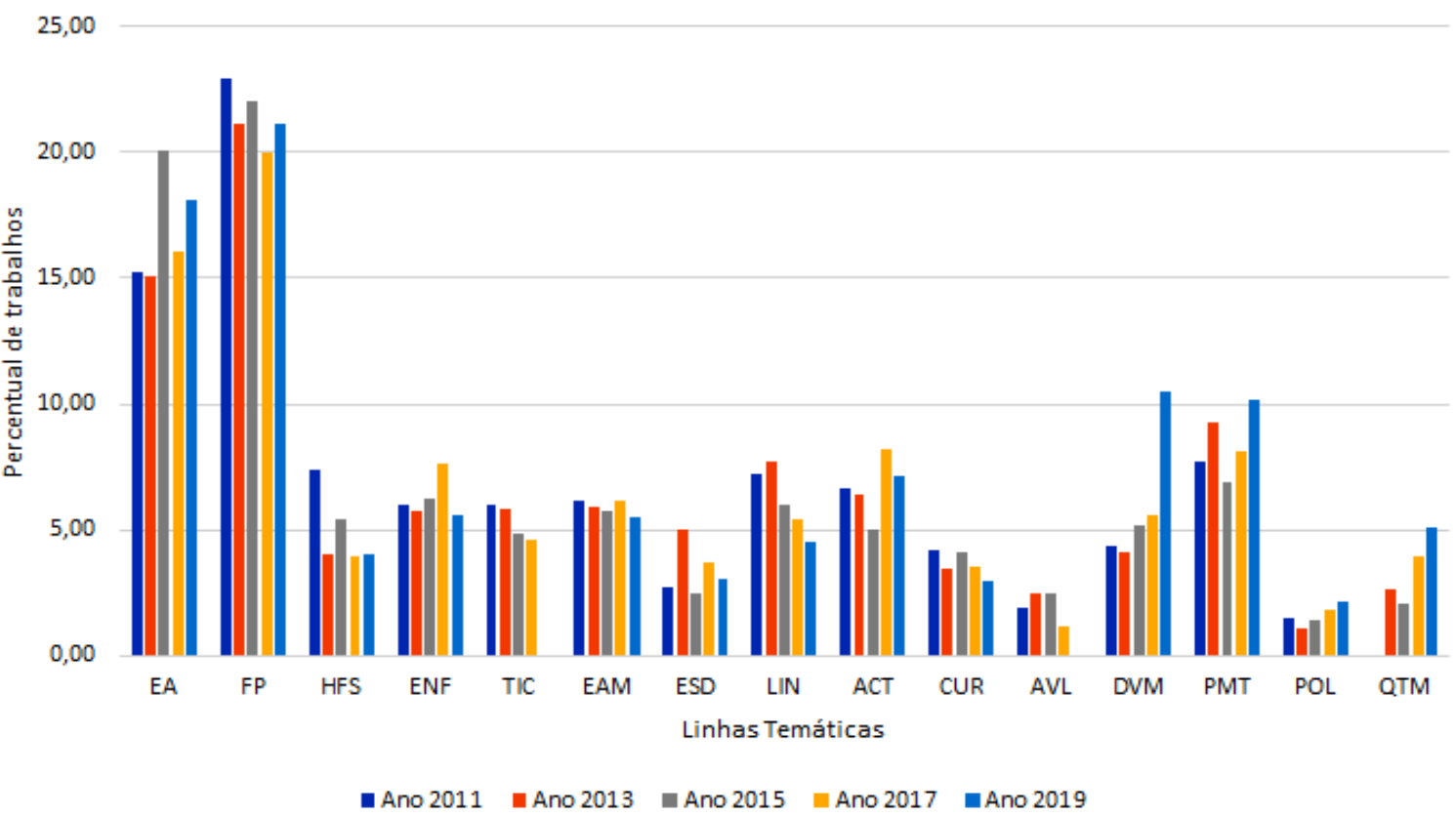

Figura 1: Percentual de trabalhos publicados no ENPEC (2011 - 2019) por linha temática Fonte: Autoria própria.

Analisando a Figura 1, pode-se verificar o movimento de alterações e consolidação de tendências. Nesse sentido, evidencia-se que as linhas temáticas que apresentaram maior percentual acompanhado pela estabilidade das produções durante as cinco edições do evento foram: "Ensino e aprendizagem de conceitos (EA)", a qual, na XI edição, em 2017, passa a ser denominada "Ensino e aprendizagem de conceitos e processos científicos", e; "Formação de professores de Ciências (FP)", que a partir do XII ENPEC, de 2019, passa a ser denominada "Formação de professores". Esse predomínio das publicações nessas linhas pode ser justificado pelo fato de as mesmas se entrecruzarem com outros temas, constituindo '[...] dois 'blocos guarda-chuva' de discussão sob os quais se abrigam todos os demais focos temáticos" (NASCIMENTO; GOUVÊA, 2020, p. 478).

Em consonância com o verificado, Slongo et al. (2015), ao realizarem um estudo a respeito dos trabalhos apresentados no ENPEC sobre formação de professores no período de 2007 a 2013, constataram que essa temática era a que se apresentava, expressivamente, em um maior número de trabalhos. Embora a metodologia empregada 
Edição Especial: I SSAPEC - Simpósio Sul-Americano de Pesquisa em Ensino de Ciências

ISSN: 2595- $4520 \quad$ Vol. 4, n. 3. 2021

pelos referidos autores seja diferente da apresentada em nossa pesquisa, os dados corroboram as informações coletadas no presente trabalho. No entanto, ao observarmos a Figura 1, podemos notar uma tendência, mesmo que pequena, de decaimento no percentual de trabalhos publicados dessa linha, porém em todos os eventos esta ainda é responsável por pelo menos $20 \%$ dos trabalhos apresentados nos ENPEC da última década.

A linha "Alfabetização Científica e Tecnológica (ACT)" apresenta certa estabilidade no período investigado, embora no ano de 2017 tenha expressado um maior número de trabalhos. É importante sinalizar que essa linha passou por duas alterações sendo a primeira no IX ENPEC (2013) em que lhe foi incorporada a temática de CTS, passando a ser denominada "Alfabetização científica e tecnológica, abordagens CTS e Educação em Ciências” e, uma segunda, no XII ENPEC (2019) na qual contou com a inserção da temática CTSA, sendo intitulada "Alfabetização científica e tecnológica, abordagens CTS/CTSA e Educação em Ciências".

Tendo isso em vista, Garcia e colaboradores (2020) ao analisarem essa linha temática, em específico, destacam o aumento no número de pesquisas da VIII para a XI edição do ENPEC, porém ressaltam que o aprimoramento teórico é um ponto a ser observado, haja vista que estas produções carecem, por vezes, de posicionamento e fundamentação quanto às vertentes teóricas adotadas e que as embasam. Além disso, ao realizarem um comparativo entre o número de pesquisas produzidas com foco em CTS/CTSA e aquelas em Alfabetização Científica e Tecnológica, submetidas ao ENPEC ao longo deste recorte temporal, os referidos autores verificaram que a produção envolvendo essa primeira temática mostrou-se mais expressiva, o que os direcionou a sugerir ainda uma outra alteração na denominação dessa linha temática do evento, qual seja: "Educação CTS/CTSA e Alfabetização Científica e Tecnológica na Educação em Ciência" (GARCIA et al., 2020, p. 160).

Em 2009, por ocasião do VI ENPEC, foi criada a linha de pesquisa "Diversidade, Multiculturalismo e Educação em Ciências (DVM)" e, dez anos depois, em 2019 no XII ENPEC, esta passou a ser denominada "Diferença, Multiculturalismo, Interculturalidade", mesmo ano em que se verifica um aumento expressivo na produção de trabalhos. Fato que pode ser decorrente da ampliação e divulgação do evento e da linha temática no campo educacional em Ciências, além das ações de grupos 
Edição Especial: I SSAPEC - Simpósio Sul-Americano de Pesquisa em Ensino de Ciências ISSN: 2595- $4520 \quad$ Vol. 4, n. 3. 2021

marginalizados e de movimentos sociais que despontaram no contexto brasileiro reivindicando que questões históricas pouco atendidas pela esfera política fossem consideradas no âmbito educacional e legal, como as relações étnico-raciais, de gênero, de pessoas com deficiências, entre outros (NASCIMENTO; GOUVÊA, 2020, p. 476).

Perante sua relevância, esses autores mencionam que a referida linha temática, “[...] de modo especial, tem se constituído numa importante instância institucional na qual a valorização da pluralidade interna ao campo tem se revelado de forma mais marcante" (2020, p. 491). Assim, essa linha nos direciona, enquanto estudantes e pesquisadores, a refletir e trazer à discussão questões problemáticas que emergem do contexto social e político, e impactam direta e/ou indiretamente no delineamento das pesquisas realizadas, trazendo para a centralidade dos debates aspectos referentes aos valores e direitos humanos.

Considerando esse movimento de diversidade e alterações nas linhas temáticas, concordamos com Slongo, Lorenzetti e Garvão (2015), ao sinalizarem que a geração de enfoques temáticos é favorecida pela consolidação do Ensino de Ciências como campo de investigação articulada a grupos de pesquisadores e linhas de pesquisa, na ampliação dos cursos de pós-graduação stricto sensu e na organização de eventos e outros meios de divulgação.

Dentre as linhas temáticas que apresentaram decrescência no número de trabalhos evidenciam-se: Tecnologias da Informação e Comunicação no Ensino de Ciências (TIC) e Avaliação (AVL), as quais, desde o XII ENPEC (2019), juntaram-se a outras linhas já constituídas. Desse modo, esta primeira foi incorporada à linha "Processos e Materiais Educativos (PMT)" e a segunda distribuída em outras linhas, quais sejam: "Ensino e aprendizagem de conceitos e processos científicos (EA)", onde consta 'abordagens e práticas de avaliação'; “Currículos (CUR)”, como 'aspectos teóricos e metodológicos de avaliação'; "Políticas educacionais (POL)", que engloba duas vertentes de trabalho, sendo 'história, análise e avaliação de políticas públicas em diferentes níveis e modalidades de ensino' e 'avaliação de sistemas educacionais'. A linha de "Formação de professores (FP)", já contava com um item relacionado à avaliação, a saber 'avaliação de modelos e práticas de formação de professores para diferentes níveis e modalidades de escolaridade'. 
Outra linha que tem apresentado diminuição no percentual de trabalhos publicados no período em questão é a de "Linguagem e Ensino de Ciências (LIN)", a qual também passou por alterações em sua denominação. De modo que, no IX ENPEC, esta passa a ser intitulada "Linguagem, Discurso e Ensino de Ciências", "Linguagem, Discurso e Educação em Ciências" no X ENPEC, e ainda "Linguagem e Discurso" no XII ENPEC.

As linhas temáticas com menores percentuais são "Educação em espaços não formais e divulgação científica (ENF), "Educação ambiental e ensino de ciências (EAM)", "Políticas Educacionais (POL)", "Currículos (CUR)" e "Educação em saúde e ensino de ciências (ESD)". Além destas, pode ser mencionada também a linha de "Questões teóricas e metodológicas da pesquisa em Educação em Ciências (QTM)" criada a partir do IX ENPEC (2013), que embora ainda apresente pouca expressividade quando comparada a outras linhas temáticas, vem demonstrando crescente produção.

Em contrapartida, na linha temática "História, Filosofia e Sociologia da Ciência na Ensino em Ciências (HFS)", é perceptível que no VIII ENPEC (2011) houve uma produção maior do que nos eventos posteriores. Esses resultados convergem com os obtidos por Silva, Werlang e Silveira (2019) ao indicarem a necessidade de se desenvolver mais pesquisas e sua divulgação/publicização nas referidas linhas temáticas, tendo em vista a importância destas para o Ensino em Ciências.

Diante do exposto, verifica-se que uma temática que poderia constituir-se enquanto uma das linhas do evento refere-se à educação inclusiva, uma vez que esta ainda é pouco abordada dentro das outras linhas temáticas, como nos revelam Schinato e Strieder (2020) ao realizarem o levantamento dos artigos publicados no ENPEC envolvendo a educação inclusiva e o Ensino de Ciências, no período de 2007 a 2017. Os resultados verificados pelas autoras sinalizam “[...] a importância de serem realizados mais estudos relacionados à inclusão de alunos deficientes na área do ensino da Ciência” (2020, p. 182). E, nesse sentido, defendemos a ideia de que a criação de uma linha com essa temática poderia direcionar olhares e reflexões a respeito de promover um Ensino de Ciências de fato inclusivo.

A esse respeito, salientamos que tal linha tem se apresentado em eventos da área de Ensino de Ciências como no Encontro Nacional de Ensino de Química (ENEQ), Encontro Nacional de Ensino de Biologia (ENEBIO) e Simpósio Nacional de Ensino de 
Edição Especial: I SSAPEC - Simpósio Sul-Americano de Pesquisa em Ensino de Ciências

ISSN: 2595- $4520 \quad$ Vol. 4, n. 3. 2021

Física (SNEF), inclusive a temática do SNEF mais recente foi "Ensino de Física no Século XXI: Caminhos para uma Educação Inclusiva”. Essa é uma temática emergente como discutem Santos e colaboradores (2020) em relação a trabalhos em Ensino de Química, e poderia ter espaço para discussão num evento da magnitude do ENPEC. Afinal, como afirmam Nascimento e Gouvêa (2020), eventos como ENPEC devem ir além da divulgação das pesquisas sobre Educação em Ciências, mas também promover "[...] o fortalecimento da democracia, dos direitos humanos, da liberdade para ensinar e aprender e com a afirmação de que a Ciência se constitui num patrimônio cultural da humanidade cujos trabalhos e resultados necessitam ser acessíveis a todas as pessoas" (p. 491).

Dado o exposto, o presente estudo possibilitou-nos compreender que as publicações por linha temática, no período investigado, comportaram-se de forma diversa, sendo que: duas são consolidadas e predominantes (Formação de Professores de Ciências e Ensino e Aprendizagem de Conceitos); duas foram suprimidas sendo uma delas incorporada em outra (Tecnologias da informação e comunicação no Ensino de Ciências à Processos e materiais educativos em Ciências) e a outra diluída em outras linhas temáticas (Avaliação e Educação em Ciências); uma foi criada (Questões teóricas e metodológicas da pesquisa em Educação em Ciências); seis apresentaram estabilidade e baixo percentual de produção (Educação em espaços não-formais e divulgação científica, Educação Ambiental e Ensino de Ciências, Políticas educacionais e Educação em Ciências; Currículos, Educação em Saúde e Ensino de Ciências e História, Filosofia e Sociologia da Ciência na Ensino em Ciências); uma sofreu déficit (Linguagens e Ensino de Ciências) e uma apresentou aumento expressivo na última edição do evento (Diversidade, Multiculturalismo e Educação em Ciências).

\section{CONSIDERAÇÕES FINAIS}

Com o presente trabalho, foi possível analisar o movimento das linhas temáticas dos últimos ENPEC, de modo a revelar a criação, supressão e incorporação de linhas temáticas ao longo do período estudado. O que, por sua vez, é fruto dos diálogos entre diferentes pesquisadores, da ampliação de pesquisas e da consolidação da área e do evento (SLONGO; LORENZETTI; GARVÃO, 2015). Bem como, do conjunto de questões e demandas emergentes da sociedade em um determinado contexto que 
Edição Especial: I SSAPEC - Simpósio Sul-Americano de Pesquisa em Ensino de Ciências ISSN: 2595- $4520 \quad$ Vol. 4, n. 3. 2021

direcionam o delineamento de pesquisas na universidade e, consequentemente, das discussões realizadas nestes eventos (NASCIMENTO; GOUVÊA, 2020).

Dessa forma, concordamos que as alterações nas linhas temáticas de eventos como o ENPEC, são derivados do interesse apresentado pela comunidade acadêmica, bem como pela demanda social. O primeiro ponto pode ser notado pela supressão, junção e criação de algumas linhas temáticas, como por exemplo, a exclusão da linha específica sobre avaliação e a criação da linha sobre questões teóricas e metodológicas. Sobre o segundo ponto, notamos que por conta dos debates acerca da diversidade e do multiculturalismo que emergiram com mais intensidade na sociedade nos últimos anos, mais trabalhos na área de Educação em Ciências com essa temática passaram a ser desenvolvidos e, por consequência, demandou a criação da linha temática Diversidade, Multiculturalismo e Educação em Ciências. Porém, nos chama a atenção que o ENPEC ainda não apresente uma linha temática sobre educação inclusiva, como já acontece em outros eventos de áreas específicas vinculadas ao Ensino de Ciências como o ENEQ, ENEBIO e o SNEF.

Ainda em relação às demandas sociais, um aspecto importante a ser sinalizado é que em 2019, pela primeira vez, o evento foi realizado na região Nordeste, já que nas outras edições esses encontros se deram nas regiões Sudeste e Sul do Brasil, o que abre um espaço enriquecedor para o diálogo com outras realidades. Além disso, o próximo encontro, será realizado no segundo semestre de 2021, pela primeira vez, na região Centro-Oeste (Caldas Novas - Goiás). Tal diversificação nas regiões de realização do evento, possibilita a participação de pesquisadores e acadêmicos das diversas regiões brasileiras.

Tendo em vista os aspectos observados, entende-se que a Pesquisa em Ensino de Ciências na década de 2010, vista sob uma perspectiva abrangente, tal qual objetivamos nesse estudo, reflete a consolidação da área nas linhas temáticas tradicionalmente investigadas e que apresentam maior representatividade nos trabalhos apresentados no evento. Bem como, sua dinamicidade frente ao contexto social, político e educacional, que direciona o olhar da comunidade científica para diferentes demandas, contribuindo para a compreensão e intervenção da Pesquisa em Ensino de Ciências em diferentes âmbitos.

\section{REFERÊNCIAS}


ABRAPEC. Sobre a ABRAPEC. [s. d.]. Disponível em:

<http://abrapecnet.org.br/wordpress/pt/sobreaabrapec/>. Acesso em 27 ago. 2020.

DELIZOICOV, D.; SLONGO, I. I. P.; LORENZETTI, L. ENPEC: 10 Anos de Disseminação da Pesquisa em Educação em Ciências. In: ENCONTRO NACIONAL DE PESQUISA EM EDUCAÇÃO EM CIÊNCIAS, 6, 2007, Florianópolis. Anais [...]. Florianópolis: ABRAPEC, 2007. Disponível em:

$<$ http://abrapecnet.org.br/atas_enpec/vienpec/autores0.html>.

ENCONTRO NACIONAL DE PESQUISA EM EDUCAÇÃO EM CIÊNCIAS, 8, 2011, Campinas. Anais [...]. Campinas: ABRAPEC, 2011. Disponível em: $<$ http://abrapecnet.org.br/atas_enpec/viiienpec/index.htm>.

ENCONTRO NACIONAL DE PESQUISA EM EDUCAÇÃO EM CIÊNCIAS, 9, 2013, Águas de Lindóia. Anais [...]. Águas de Lindóia: ABRAPEC, 2013. Disponível em: <http://abrapecnet.org.br/atas_enpec/ixenpec/atas/>.

ENCONTRO NACIONAL DE PESQUISA EM EDUCAÇÃO EM CIÊNCIAS, 10, 2015, Águas de Lindóia. Anais [...]. Águas de Lindóia: ABRAPEC, 2015. Disponível em: <http://www.abrapecnet.org.br/enpec/X-enpec/anais2015/trabalhos.htm>.

ENCONTRO NACIONAL DE PESQUISA EM EDUCAÇÃO EM CIÊNCIAS, 11, 2017, Florianópolis. Anais [...]. Florianópolis: ABRAPEC, 2017. Disponível em: <http://www.abrapecnet.org.br/enpec/xi-enpec/anais/trabalhos.htm>.

ENCONTRO NACIONAL DE PESQUISA EM EDUCAÇÃO EM CIÊNCIAS, 12 , 2019, Natal. Anais [...]. Natal: ABRAPEC, 2019. Disponível em:

<http://abrapecnet.org.br/enpec/xii-enpec/anais/index.htm>.

FLICK, U. Introdução à pesquisa qualitativa. 3. ed. Porto Alegre: Artmed, 2009.

GARCIA, B.; OLIVEIRA, A.; LORENZETTI, L.; ZANLORENZI, M. A. As pesquisas sobre Educação Ciência, Tecnologia e Sociedade/Ambiente e alfabetização científica e tecnológica socializadas no ENPEC (2011-2017). Amazônia, Belém, v. 16, n. 37, p. 151-163. 2020. Disponível em:

<https://www.periodicos.ufpa.br/index.php/revistaamazonia/article/view/7900/6695>.

KRUPCZAK, C.; SILVEIRA, C. A produção acadêmica da região Nordeste: uma análise nas atas do encontro nacional de pesquisa em educação em ciências. Revista

Eletrônica Científica Ensino Interdisciplinar, Rio Grande do Norte, v. 5, n. 15, 2019.

Disponível em:

<http://natal.uern.br/periodicos/index.php/RECEI/article/view/1692/2245>.

LORENZETTI, L.; SILVA, T. F. da; BUENO, T. N. N. A Pesquisa em Ensino de Química nos ENPECS (1997 a 2013): mapeando tendências. In: ENCONTRO 
NACIONAL DE PESQUISA EM EDUCAÇÃO EM CIÊNCIAS, 10, 2015, Águas de Lindóia. Anais [...]. Águas de Lindóia: ABRAPEC, 2015. Disponível em: <http://www.abrapecnet.org.br/enpec/x-enpec/anais2015/resumos/R0342-1.PDF>.

LÜDKE, M.; ANDRÉ, M. E. D. A. Pesquisa em educação: abordagens qualitativas. 2. ed. São Paulo: EPU, 2013.

NARDI, R. Formação da área de ensino de ciências no Brasil: fatores que contribuíram para a constituição e consolidação da pesquisa e suas características segundo destacados pesquisadores brasileiros. In: NARDI, R.; GONÇALVES, T. V. O. A pós-graduação em ensino de ciências e matemática no Brasil: origens, características, programas e consolidação da pesquisa na área. São Paulo: Livraria da Física, 2014, p. 17-55.

Disponível em: <https://periodicos-

des.cecom.ufmg.br/index.php/rbpec/article/download/4098/2662>.

NASCIMENTO, H. A. S. do; GOUVÊA, G. Diversidade, Multiculturalismo e Educação em Ciências: Olhares a partir do Enpec. Revista Brasileira de Pesquisa em Educação em Ciências, Belo Horizonte, p. 469-496, 2020. Disponível em: <https://periodicos.ufmg.br/index.php/rbpec/article/view/19614/19341>.

PEREIRA, T. Z. M.; SILVEIRA, C. A produção acadêmica da região Norte: uma análise na ata do XI Encontro Nacional de Pesquisa em Educação em Ciências. Rede Amazônica de Educação em Ciências e Matemática, Cuiabá, v. 7, n. 2, p. 245-260, 2019. Disponível em:

<https://periodicoscientificos.ufmt.br/ojs/index.php/reamec/article/view/8726>.

SANTOS, K. S.; GALIETA, T. Ensino de Ciências e Educação Inclusiva: uma análise dos trabalhos apresentados no ENPEC. In: ENCONTRO NACIONAL DE PESQUISA EM EDUCAÇÃO EM CIÊNCIAS, 12, 2019, Natal. Anais [...]. Natal: ABRAPEC, 2019. Disponível em: <http://abrapecnet.org.br/enpec/xiienpec/anais/resumos/1/R1657-1.pdf >.

SANTOS, P. M. S.; NUNES, P. H. P.; WEBER, K. C.; LIMA Jr, C. G. Educação inclusiva no Ensino de Química: uma análise em periódicos nacionais. Educação Especial, Santa Maria, v. 33, p. 1-19, 2020. Disponível em <https://periodicos.ufsm.br/educacaoespecial/article/view/36887>.

SÁ-SILVA, J. R.; ALMEIDA, C. D. de; GUINDANI, J. F. Pesquisa documental: pistas teóricas e metodológicas. Revista Brasileira de História e Ciências Sociais, Ano I - Número I - Julho de 2009. Disponível em:

<https://www.rbhcs.com/rbhcs/article/viewFile/6/pdf>. 
Edição Especial: I SSAPEC - Simpósio Sul-Americano de Pesquisa em Ensino de Ciências

ISSN: 2595- $4520 \quad$ Vol. 4, n. 3. 2021

SCHINATO, L. C. S.; STRIEDER, D. M. Educação inclusiva no campo da pesquisa no Ensino de Ciências: artigos publicados no evento ENPEC. Hipátia, São Paulo, v. 5, n. 1, p. 168-185, jun. 2020. Disponível em:

<https://ojs.ifsp.edu.br/index.php/hipatia/article/download/1446/991/>.

SILVA, T. G. I. da; WERLANG, J.; SILVEIRA, C. Análise da Produção acadêmica da região Centro-Oeste no ENPEC. In: ENCONTRO NACIONAL DE PESQUISA EM EDUCAÇÃO EM CIÊNCIAS, 12, 2019, Natal. Anais [...]. Natal: ABRAPEC, 2019. Disponível em: <http://abrapecnet.org.br/enpec/xii-enpec/anais/resumos/1/R04901.html>.

SILVA, R. H. R; GAMBOA, S. S. Análise epistemológica da pesquisa em Educação Especial: a construção de um instrumento de análise. Atos de Pesquisa em Educação, Blumenau-SC, v. 6, n. 2, p. 373-402, mai./ago. 2011. Disponível em:<https://proxy.furb.br/ojs/index.php/atosdepesquisa/article/view/2581>.

SILVEIRA, C.; MIRANDA, A. C. Tendências das pesquisas da Educação do Campo a partir da análise de publicações nos anais do ENPEC. Revista Insignare Scientia - RIS, v. 2, n. 2, p. 76-99, 16 set. 2019. Disponível em:

<https://periodicos.uffs.edu.br/index.php/RIS/article/view/10809/7202>.

SLONGO, I. I. P.; LORENZETTI, L.; GARVÃO, M. A pesquisa em educação em ciências disseminada no ENPEC (2007 a 2013): explicitando dados e analisando tendências. In: ENCONTRO NACIONAL DE PESQUISA EM EDUCAÇÃO EM CIÊNCIAS, 10, 2015, Águas de Lindóia. Anais [...]. Águas de Lindóia: ABRAPEC, 2015. Disponível em: <http://www.abrapecnet.org.br/enpec/xenpec/anais2015/resumos/R1075-1.PDF>.

TREMBLAY, M. A. (1985). Une première saison em Acadie ou comment je suis devenu anthropologue sans le savior. In: GENEST, S. (org). La passion de l'echange: terrain d'anthropologues du Québec. Chicoutimi: Gaêtan Morin, p. 15-52. Apud CELLARD, A. A análise documental. In: POUPART, J. et al. (Orgs.). A pesquisa qualitativa: enfoques epistemológicos e metodológicos. Petrópolis: Vozes, 2012.

YAMAZAKI, R. M. O.; DELIZOICOV, D. Educação escolar indígena e a educação em ciências: um mapeamento das publicações no ENPEC e ANPED. In: ENCONTRO NACIONAL DE PESQUISA EM EDUCAÇÃO EM CIÊNCIAS, 9, 2013, Águas de Lindóia. Anais [...]. Águas de Lindóia: ABRAPEC, 2013. Disponível em: <http://abrapecnet.org.br/atas_enpec/ixenpec/atas/resumos/R1453-1.pdf>. 